\title{
As traduções literárias nas relações culturais romeno-portuguesas
}

\section{Veronica MANOLE}

Univerdade Babeş-Bolyai / Camões I. P. / Universidade Paris 8 Roménia / Portugal / França

\section{Iolanda VASILE}

Centro de Estudos Sociais Coimbra / Universidade de Coimbra Portugal

Resumo : Este artigo destaca a importância do papel das traduções literárias nas relações culturais entre a Roménia e Portugal. Desenvolvemos a nossa análise a partir de dois critérios, o contexto histórico e o cânone ocidental. Concentramo-nos nas traduções de nove escritores, acrescentando à nossa investigação as opiniões dos tradutores mais representativos dos dois países.

Palavras chave : traduções, literatura romena, literatura portuguesa, relações culturais.

Abstract: This article outlines the importance of the role played by literary translations in the Romanian - Portuguese cultural relations. We develop our analysis based on two criteria: the historical-political context and the Western literary canon. We further focus on translations from nine writers, completing our research with views from a few of the main translators on both sides.

Keywords: translations, Romanian literature, Portuguese literature, cultural relations.

\section{Introdução}

As traduções literárias foram sempre veículos e mediadores entre culturas, papéis alcançados com o bom empenho dos tradutores. Nesse sentido, as relações romeno-portuguesas não são uma exceção. Povos situados nos extremos da România Velha, os portugueses e os 
romenos conhecem uma aproximação tardia. Embora os primeiros contactos remontem ao século $\mathrm{XV}^{1}$, é sobretudo no século $\mathrm{XX}$ que as relações diplomáticas ${ }^{2}$, económicas e culturais entre os dois países se desenvolvem.

No que diz respeito às pontes culturais, devemos mencionar as atividades de personalidades, como Nicolae Iorga 3 , Mircea Eliade ou Lucian Blaga, que contribuíram para o conhecimento mútuo dos dois povos. Durante o seu mandato de assessor de imprensa na legação romena de Lisboa, Mircea Eliade teve uma atividade cultural intensa, publicando em revistas portuguesas artigos sobre a cultura romena e dedicando-se à redação de um livro sobre Salazar. Enquanto ministro plenipotenciário da Roménia em Portugal, o poeta e filósofo Lucian Blaga foi influenciado pela paisagem da costa portuguesa e publicou uma série de poemas que será intitulada pelos críticos da sua obra poética «o ciclo lusitano». Na Roménia, o escritor Mateiu Caragiale conheceu o diplomata Martinho de Brederode 4 , cujo livro A morte do amor (1894), publicado em Portugal com o pseudónimo Marco Sponti, provavelmente influenciou o enredo do romance Craii de Curtea Veche (1929).

$\mathrm{Na}$ área do trabalho académico da Roménia, a literatura portuguesa beneficiou de estudos importantes. Professores e investigadores romenos, formados na Roménia e em Portugal 5 têm contribuições notáveis na área dos estudos literários portugueses. Em 1978 Roxana Eminescu defende uma tese de doutoramento sobre Fernando Pessoa; é autora de volumes sobre a literatura portuguesa publicados na Roménia e em Portugal, como Preliminarii la o istorie a literaturii portugheze [Preliminares a uma história da literatura portuguesa] (1979) e Novas coordenadas no romance português (1983). Mihai Zamfir dedica-se ao estudo e ensino da literatura portuguesa, sendo autor do volume Formele liricii portugheze [As formas da lírica portuguesa] $(1985,2003)$ e de numerosos artigos publicados em revistas culturais; Mioara Caragea verte para o romeno uma grande parte da obra de José Saramago e dedica-lhe uma tese de doutoramento, publicada com o título A leitura da história nos romances de José Saramago (2003). Micaela Ghițescu faz um trabalho incessante, conseguindo verter para o romeno dezenas de obras da

\footnotetext{
${ }^{1}$ D. Pedro, Infante de Portugal (1393-1449) e Dan II, príncipe da Valáquia participaram em 1426 na campanha do imperador Sigismundo de Luxemburgo contra os hussitas.

2 Segundo as informações do site oficial do Ministério de Negócios Estrangeiros da Roménia, as relações diplomáticas entre os dois países começam na segunda década do século XX: http://www.mae.ro/bilateral-relations/1732 (última consulta 4 de agosto de 2013).

3 Nicolae Iorga publica o volume Țara latină cea mai îndepărtată din Europa: Portugalia [O país latino mais afastado da Europa: Portugal] (1928), constituído de impressões sobre a viagem a Portugal e de quatro conferências sobre a cultura portuguesa.

4 Sobre a relação entre Mateiu Caragiale e Martinho de Brederode veja-se Zamfir \& Perdigão (1998) e sobre a atividade diplomática do português veja-se Stoica (2011).

5 Destacamos a importância da abertura do leitorado romeno de Lisboa nos anos '40 e do leitorado português de Bucareste em 1974.
} 
literatura portuguesa e sendo autora de estudos que tratam as traduções romenas de Eça de Queirós (2000a), a presença da cultura luso-brasileira na Roménia (200ob), entre outros.

Houve também avanços no que diz respeito ao quadro institucional que permite a divulgação dos autores nacionais através da tradução. Em 2007 é inaugurada a sucursal de Lisboa do Instituto Cultural Romeno (doravante ICR), que tem programas de apoios à tradução, incentivando a publicação de autores como Ana Blandiana, Mircea Eliade, Gabriela Adameşteanu, Dinu Flămând. O Camões Instituto da Cooperação e da Língua, I.P. e a Direção Geral do Livro e das Bibliotecas de Lisboa têm programas de apoio às traduções de obras portuguesas, graças aos quais volumes de autores como Fernando Pessoa, Manuel Alegre, Teolinda Gersão, José Saramago, António Lobo Antunes ${ }^{6}$, entre outros, foram traduzidos em romeno.

Esta sucinta introdução não pretende ser completa7, o nosso objetivo sendo apenas evidenciar momentos dos encontros culturais romeno-portuguesas que considerámos relevantes para contextualizar o lugar das traduções literárias. De certeza outros autores e obras mereceriam destaque, mas as limitações de espaço deste trabalho e o seu foco virado para a tradução literária determinou uma abordagem mais sintética.

Nas próximas secções debruçar-nos-emos sobre algumas das traduções literárias publicadas em volume ${ }^{8}$ nos dois países, como também beneficiaremos da opinião ${ }^{9}$ de alguns dos tradutores envolvidos neste processo. A escolha das obras que apresentaremos foi feita com base em dois critérios, o contexto histórico-político e a configuração do cânone literário ocidental ${ }^{10}$. O critério históricopolítico tem em vista as duas mudanças políticas transformadoras nos dois países, o golpe de Estado de 25 de Abril de 1974 que derrubou o

\footnotetext{
${ }^{6}$ Uma lista atualizada das traduções romenas publicadas com o apoio do Camões I. P. está disponível no site oficial da instituição:

http://c1.camoes.cdn.cloudapp.pt/images/stories/ edicao/edestrangeiro_jul13.pdf (última consulta a 22 de agosto de 2013).

7 Para uma descrição mais pormenorizada das relações históricas e culturais entre a Roménia e Portugal veja-se Peixoto da Fonseca (1989) e Silva Perdigão (1998).

8 A pesquisa bibliográfica para este artigo foi feita em agosto de 2013 nos catálogos eletrónicos da Biblioteca Centrală Universitară da Universidade Babeş-Bolyai, Biblioteca Academiei [Biblioteca da Academia] de Bucareste, da Biblioteca Centrală Universitară [Biblioteca Central Universitária] da Universidade de Bucareste, da Biblioteca Nacional de Portugal (Lisboa) e Biblioteca da Universidade de Coimbra (Coimbra). Utilizámos também a lista compilada pela secção cultural da Embaixada de Portugal de Bucareste, disponível online

http://embportugal.ro/documents/Autores\%2otraduzidos_jan13.pdf (última consulta 23 de agosto de 2013).

9 Agradecemos a Daniel Nicolescu, diretor do Instituto Cultural Romeno em Lisboa, e aos tradutores Clarisa Lima e Corneliu Popa as entrevistas concedidas para este trabalho.

10 No Westhern Canon (1994) de Harold Bloom são mencionados os seguintes autores portugueses: Luís Vaz de Camões, António Ferreira, Eça de Queiroz, Fernando Pessoa, Jorge de Sena, José Saramago, José Cardoso Pires, Sophia de Mello Breyner e Eugénio de Andrade.
} 
poder fascista e o regime colonial em Portugal e a revolução de Dezembro de 1989 na Roménia, que trouxe o fim de um dos regimes comunistas mais duros da Europa. Os dois momentos representaram marcos fundamentais para os processos de transformação e abertura nas respetivas sociedades que ainda lutam com a reconstrução das suas memórias e a reescrita de narrativas históricas lineares. Neste contexto, em termos editorais, as novas aberturas representaram também o acesso a publicações, traduções e leituras anteriormente proibidas pelas censuras ditatoriais, ou simplesmente novas maneiras de escrever, desprendidas de quaisquer restrições censórias.

\section{Traduções de obras portuguesas}

Há pouco mais de um século e meio ${ }^{11}$ surgiu na Roménia a primeira tradução de um texto literário português. Desde então foram publicados quase duzentos volumes de obras portuguesas, algumas com várias edições. Estão disponíveis em romeno traduções de autores clássicos, como Mariana Alcoforado, Luís Vaz de Camões, Camilo Castelo Branco, Almeida Garrett, Alexandre Herculano, Fernão Mendes Pinto, Eça de Queiroz ${ }^{12}$, de modernistas como Mário de Sá-Carneiro e Fernando Pessoa, mas também de escritores do século XX e contemporâneos, como Almeida Faria, Teolinda Gersão, António Lobo Antunes, Dinis Machado, José Luís Peixoto, José Saramago, Gonçalo M. Tavares, Urbano Tavares Rodrigues, Rui Zink, entre outros. Um romeno que não lê em português pode, através das traduções disponíveis, ter um panorama relevante sobre a literatura portuguesa nas suas diferentes etapas de desenvolvimento, mas a situação das traduções portuguesas de obras literárias romenas é bem diferente.

Nesta secção concentrar-nos-emos no acervo de versões romenas de quatro autores portugueses, Luís Vaz de Camões, Fernando Pessoa, José Saramago, presentes no cânone de Bloom, e José Luís Peixoto, uma das figuras representativas da nova geração de jovens escritores portugueses. Apresentaremos os tradutores e faremos breves considerações sobre o contexto sócio-cultural em que estes eventos editoriais aconteceram.

\subsection{Luís Vaz de Camões (1524-1580)}

Há três volumes com versões em romeno de obras de Luís Vaz de Camões: um traduzido por H. R. Radian, dedicado à lírica, Sonete

\footnotetext{
${ }^{11}$ Segundo Ploae-Hanganu $(1995,237)$ foram publicados em 1861 traduções de breves trechos da obra de Gil Vicente, d'Os Lusíadas e de alguns sonetos de Camões, bem como fragmentos das cartas de amor de Mariana Alcoforado.

12 Ghițescu faz uma apresentação detalhada das traduções das obras deste escritor português (2000a), descrevendo a história das versões romenas de obras queirosianas publicadas em revistas a partir dos anos '20 (por vezes traduções feitas a partir de outras línguas, como o espanhol) e a publicação em volume dos romances a partir da década dos '60, até 2000.
} 
[Sonetos] (1974) ${ }^{13}$ e duas edições d'Os Lusíadas (1965/1977), na tradução de Aurel Covaci.

A publicação da tradução da epopeia camoniana em 1965 é sem dúvida um dos momentos marcantes dos encontros culturais romenoportugueses, em primeiro lugar, por propiciar ao público romeno acesso a uma das obras mais proeminentes da literatura portuguesa $\mathrm{e}$ em segundo lugar, porque a tradução em si é um ato estético excecional. Aurel Covaci achou uma variante muito inspirada para a tradução do título, optando por Lusiada, e não pela tradução literal, que seria Lusiazii, posicionando a obra camoniana ao lado das grandes epopeias clássicas, Iliada de Homero ou Eneida de Virgílio. Outra particularidade da tradução de Covaci é a preservação da métrica original de Camões, oitavas com rima cruzada nos primeiros seis versos e emparelhada nos últimos dois ( $\mathrm{AB}, \mathrm{AB}, \mathrm{AB}, \mathrm{CC})$. Lusiada foi republicada em 1977 numa coletânea intitulada Biblioteca pentru toți [Biblioteca para todos] da editora Minerva, em que apareceram em formato de livro de bolso as grandes obras da literatura romena e estrangeira. Passadas mais de três décadas desta segunda edição, consideramos necessária a republicação da versão romena da epopeia camoniana em condições gráficas modernas para a repor em circulação junto do público mais jovem.

\subsection{Fernando Pessoa (1888-1935)}

A obra de Fernando Pessoa tem uma penetração profunda no espaço cultural romeno. A primeira publicação em volume deve-se a Roxana Eminescu, responsável pela tradução e pelo prefácio do volume Ploaie oblică [Chuva oblíqua] (1980). Com pouco mais de 150 páginas, este volume contém uma seleção representativa da obra poética de Fernando Pessoa e dos seus heterónimos Alberto Caeiro, Álvaro de Campos e Ricardo Reis. Até à publicação de outro volume pessoano vai haver um hiato de mais de uma década, que será interrompido pela edição trilingue, em romeno, português e espanhol da obra do heterónimo Alberto Caeiro, Păstorul de turme [O guardador de rebanhos] (1992), concebida pelo hispanista Mihai Catuniari. Três anos mais tarde, aparece na editora Est Bancherul anarhist [O banqueiro anarquista] (1995), vertido em romeno por Micaela Ghițescu.

Em 2000 assistimos a dois lançamentos importantes para a obra pessoana e o seu percurso no mercado editorial romeno. Aliás, é a partir desta data que a obra de Fernando Pessoa começa a ser traduzida e publicada sistematicamente na Roménia. Micaela Ghițescu publica na Editura Ştiințifică o volume Terapia eliberării [A terapia da libertação] (2000), em que são incluídos crónicas e fragmentos com opiniões do poeta sobre a vida política e social. Neste volume, prefaciado por José Augusto Seabra, encontramos páginas sobre Salazar, a situação da

\footnotetext{
13 Sendo o nosso foco a dinâmica das traduções literárias, mencionaremos apenas os anos da primeira edição da tradução.
} 
Maçonaria em Portugal e críticas virulentas contra o comunismo. A segunda publicação de 2000, possível graças ao apoio do programa do Camões I. P. para a edição de obras portuguesas no estrangeiro, será na Editura Fundației Culturale Române. Trata-se de uma edição em dois volumes de Cartea neliniştirii [O livro do desassossego] (2000), na tradução do poeta Dinu Flămând. Nos anos seguintes o mesmo tradutor publica na editora Univers o volume Odă maritimă şi alte poeme [Ode marítima e outros poemas] (2002), prefaciado por José Augusto Seabra e, na editora Paralela 45, uma edição de poemas de Ricardo Reis, Odes e outros poemas / Ode şi alte poeme (2004).

A editora Humanitas cria uma série de autor Fernando Pessoa, publicando nos últimos anos os seguintes volumes: a segunda edição de Cartea neliniştirii [O livro do desassossego] (2009), Opera poetică [Obra poética] (2011), ambos na tradução de Dinu Flămând, e Ultimatum şi alte manifeste [Ultimato e outros manifestos] (2012), na tradução de Dinu Flămând e Micaela Ghițescu. A segunda edição de Cartea neliniştirii [O livro do desassossego] (2009) não é apenas uma republicação da variante que apareceu em 2000; como explica o tradutor no prefácio, trata-se de uma reedição feita a partir da versão de Richard Zenith. A tradução foi também revista, à luz das novas reinterpretações dos fragmentos pessoanos. Os volumes de 2009, 2011 e 2012 têm prefácios consistentes com análises literárias, apresentações cronológicas da vida do autor e notas de rodapé para facilitar a leitura. Trata-se de um trabalho profundo de tradução e de exegese feito pelo tradutor, que é também um dos poetas de destaque da literatura romena contemporânea ${ }^{14}$.

Fernando Pessoa é considerado no espaço cultural romeno um autor de importância fundamental, os volumes que apareceram foram resenhados nas revistas de cultura mais importantes do país e Uniunea Scriitorilor din România (União dos Escritores da Roménia) galardoou Dinu Flămând com o prémio nacional de tradução pelos volumes Cartea neliniştirii [O livro do desassossego] (2000) e Opera poetică [Obra poética] (2011).

\subsection{José Saramago (1922-2010)}

O autor português mais traduzido na Roménia é sem dúvida José Saramago. Entre 1988 e 2013 apareceram nas editoras Univers e Polirom versões romenas das seguintes obras ${ }^{15}$ : Memorialul mânăstirii [O memorial do convento] (1988/1998), Istoria asediului Lisabonei [História do cerco de Lisboa] (1997), Evanghelia după Isus Cristos [O

\footnotetext{
14 Dinu Flămând recebeu em 2011 o prémio nacional de poesia “Mihai Eminescu”.

15 Houve várias edições dos romances de Saramago, mas por falta de espaço vamos mencionar apenas a primeira edição, exceto no caso do romance Memorial do convento, que apareceu com dois títulos. Antes da revolução romena de 1989 foi publicado com o título Memorialul de la Mafra [O memorial de Mafra], porque a censura não permitia a publicação da palavra "mânăstire" [convento]. Nas edições e reedições que se seguiram depois de 1989 conseguiu-se recuperar o título original, Memorialul mânăstirii [O memorial do convento].
} 
Evangelho segundo Jesus Cristo] (1999), Toate numele [Todos os nomes] (2002), Anul morții lui Ricardo Reis [O ano da morte de Ricardo Reis] (2003), Eseu despre orbire [Ensaio sobre a cegueira] (2005), Peştera [A caverna] (2005), Călătoria elefantului [A viagem do elefante] (2010), traduzidos por Mioara Caragea; Intermitențele morții [As intermitências da morte] (2007), Eseu despre luciditate [Ensaio sobre a lucidez] (2008), Omul duplicat [O homem duplicado] (2009), Fărâme de memorii [As pequenas memórias] (2009), Manual de pictură şi caligrafie [Manual de pintura e caligrafia] (2010), na tradução de Georgiana Bărbulescu; Caietul. Texte scrise pentru blog: septembrie 2008 - martie 2009 [O Caderno] (2010), Ultimul caiet. Texte scrise pentru blog: martie 2009 - noiembrie 2009 [O Caderno 2] (2011), Cain [Caim] (2012), Lucarna [Claraboia] (2013) traduzidos por Simina Popa; Pluta de piatră [A jangada de pedra] (1990), Călătorie prin Portugalia [Viagem a Portugal] (2011) na tradução de Mirela Stănciulescu.

As primeiras traduções beneficiaram do apoio do Instituto do Livro de Lisboa e foram publicadas pela Univers ${ }^{16}$, mas a partir de 2001 a obra de Saramago passa a ser publicada pela Polirom. Atualmente os livros são editados em condições gráficas excelentes, numa série de volumes de capa dura, alguns sendo também incluídos na coletânea Top $10+$, que contém livros de bolso a preços mais acessíveis e outros vendem-se em formato ebook. Mais recentemente, Camões I. P. apoiou a tradução e a edição do romance $A$ viagem do elefante (2010).

$\mathrm{O}$ facto de ter sido galardoado com o prémio Nobel teve de certeza influência no interesse dos editores pelas obras de Saramago, mas alguns volumes foram publicados antes de 1998 também. Mioara Caragea, a tradutora a quem devemos oito versões romenas do Nobel português, recebeu os prémios da Sociedade de Língua Portuguesa, do Salão Literário de Cluj e da Associação dos Editores Romenos pelo seu trabalho. Os volumes têm prefácios e estudos críticos assinados por Mioara Caragea, Pilar del Rio e Umberto Eco, que oferecem chaves de leitura, pistas de interpretação de uma obra com referências culturais por vezes difíceis para os leitores romenos. Observamos também o uso consistente de notas de rodapé, sobretudo no caso de obras em que abundam as referências à história de Portugal ou os jogos intertextuais com outros autores portugueses, como é o caso do romance $O$ ano da morte de Ricardo Reis.

As dificuldades em verter Saramago para o romeno relacionamse com o estilo da sua escrita, que usa a pontuação para conferir ao texto um ritmo próprio, com as estratégias intertextuais através das quais o escritor dialoga com outros textos da literatura portuguesa e

\footnotetext{
${ }^{16} \mathrm{O}$ testemunho de Mioara Caragea sobre a fraude da editora Univers foi publicado pela revista Observator cultural, $\mathrm{n}^{\mathrm{O}}$ 201-202, janeiro, 2004 e está disponível online http://www.observatorcultural.ro/Precizare-la-precizare*articleID_9946articles_details.html (última consulta a 22 de agosto de 2013).
} 
universal ou com os versículos bíblicos ${ }^{17}$, e com a adaptação das referências históricas e culturais. Consideramos que uma análise detalhada do trabalho dos quatro «laboratórios de tradução» que ofereceram ao público romeno acesso ao universo de José Saramago, tomando em consideração aspetos das transferências culturais e estilísticas, deveria ser feita no futuro.

\subsection{José Luís Peixoto (n. 1974)}

Galardoado com vários prémios literários em Portugal e no estrangeiro, entre os quais o prémio José Saramago pelo romance Nenhum olhar em 2001, é um dos mais proeminentes jovens escritores portugueses e tem já uma obra variada, com volumes de ficção, poesia, literatura infantil e de viagem, peças de teatro. Na Roménia a Polirom publicou Nici o privire [Nenhum olhar] (2009) e Cimitirul de piane [Cemitério de pianos] (2010), traduzidos por Clarisa Lima.

José Luís Peixoto ainda não é para o grande público romeno um autor com a visibilidade de Pessoa ou Saramago, apesar de no ambiente cultural a sua obra ter sido elogiada há mais de uma década ${ }^{18}$. Na altura da participação do escritor no Festival Internacional de Literatura de Bucareste em 2009, revistas culturais romenas publicaram crónicas sobre a sua obra, o autor deu muitas entrevistas, que o tornaram conhecido. No ano seguinte, quando foi publicada a tradução do romance Cemitério de pianos (2010), resenhas elogiosas ${ }^{19}$ publicadas em revistas culturais apresentaram José Luís Peixoto como um dos grandes autores contemporâneos.

\section{Traduções de obras romenas}

Segundo Fonseca (1989), o romance João [Ion] de Liviu Rebreanu é a primeira tradução portuguesa da literatura romena publicada em volume e data talvez de 1940. Muitos passos foram dados até ao presente, sendo o nosso propósito apresentar nesta secção um quadro das traduções da literatura romena realizadas em Portugal, com destaque apenas para algumas delas, em função dos critérios que empregámos também na seleção das traduções de obras portuguesas: o cânone literário e contexto histórico-político.

Um olhar amplo sobre o quadro completo de traduções de autores romenos revela uma prevalência na escolha de escritores canónicos, mas também uma abertura mais recente para novos nomes quando o ICR lança dois programas de apoio à tradução, «20 autores», que contempla 0 apoio à tradução e publicação de 20 nomes da literatura romena contemporânea escolhidos por um júri especializado,

\footnotetext{
${ }_{17}$ Referimo-nos especialmente ao romance O Evangelho segundo Jesus Cristo, que abunda em referências ao texto bíblico.

18 «José Luís Peixoto», em România literară, de Mihai Zamfir (2002).

19 «Excelența literaturii lui Peixoto» [A excelência da literatura de Peixoto] de Dana Pîrvan-Jenaru (2010) em Observator cultural [Observatório cultural].
} 
e o «Translation and Publication Support» (doravante TPS), (2006), que oferece financiamento para editores estrangeiros que queiram publicar autores romenos. A seleção dos autores a partir de um cânone literário é justificada pelos editores com um leque de argumentos, como as necessidades de mercado, o reconhecimento mundial de certos nomes, como Emil Cioran, Eugen Ionesco e Norman Manea, ou o destaque de alguns pela sua relação com Portugal, se pensamos em Lucian Blaga ou Mircea Eliade. Contudo, os programas do ICR «20 autores» e TPS são duas ações que facilitaram o encontro do público português com novos nomes da literatura romena, como Mircea Cărtărescu e Gabriela Adameşteanu. Se o caminho que foi iniciado é salutar, muitos passos ficam ainda por dar, uma vez que, desde o lançamento dos dois programas em Portugal, do total de aproximadamente 13 livros $^{20}$ traduzidos neste intervalo de tempo, somente seis beneficiaram dos respetivos financiamentos ${ }^{21}$.

A seguir, optaremos por destacar apenas cinco escritores romenos traduzidos em Portugal: Mihai Eminescu, Lucian Blaga, Mircea Eliade, Ana Blandiana e Gabriela Adameşteanu.

\subsection{Mihai Eminescu (1850-1889)}

$\mathrm{O}$ poeta nacional romeno ${ }^{22}$ por excelência, confundiu o seu percurso de vida com a escrita nas suas múltiplas formas, dedicando-se, por algum tempo, também ao jornalismo. Com temas variados, mas explorando em particular o par natureza-amor, Eminescu alcança, por isso, a empatia e compreensão de inúmeros leitores, transformando-se, com os anos, num autor canónico.

Eminescu beneficia de traduções em inúmeros idiomas. Em Portugal $^{23}$ apareceu uma edição bilingue intitulada Revedere, de 2005, na editora independente Evoramons (Castelo Branco), na tradução de Doina Zugrăvescu. $O$ volume reúne 21 poemas magistralmente traduzidos, que mantêm a prosódia original (Zamfir 2005). Lembramos também uma antologia literária que saiu em 2004 - Dois mil e quatro antologia Literária, em Lisboa, na Editora Cavalo de Ferro, que promove 14 autores estrangeiros. Dentre estes, quatro são romenos, Eminescu sendo incluído com a tradução de Dan Caragea da obraprima Luceafărul [Vésper]. Como Mihai Zamfir mostra, esta também é

\footnotetext{
${ }^{20}$ A contagem não inclui edições bilingues ou traduções publicadas em coletâneas ou sob qualquer outra forma.

${ }^{21}$ Informação fornecida pela assessoria do Instituto Cultural Romeno em Lisboa (doravante ICRL), por e-mail, em 2 de Agosto de 2013.

${ }^{22}$ A inevitável ligação entre os dois poetas símbolos nacionais, Camões e Eminescu, é uma analogia à mão e Mircea Eliade foi o primeiro a debruçar-se sobre ela no artigo Camões e Eminescu, publicado em 1942, no semanário Acção.

23 Não faltam também os eventos ou artigos que, em Portugal, referenciam o grande poeta. Em 15 de Janeiro de 2013, no dia da cultura romena, escolhida a partir do dia de nascimento de Eminescu, o ICRL comemora 163 do nascimento do autor com um concurso de tradução do poema Floare albastră [Flor azul].
} 
uma variante intensamente trabalhada, que em muitos aspetos se aproxima da prosódia original.

Contudo, a primeira entre as edições em português das poesias de Eminescu intitulada Eminescu. Poezii [Eminescu. Poesias] data de 1950 e foi editada também em edição bilingue pela editora Fernandes, numa tradução de Victor Buescu, que teve a colaboração de Carlos Queiroz. O livro conta também com um ensaio de Mircea Eliade, «Eminescu - poeta da raça romena», publicado inicialmente no semanário Acção.

Uma outra edição bilingue, com uma seleção da obra de Eminescu, é publicada em 2004, em Bucareste, na editora Boris David, pseudónimo do seu tradutor, também escritor, Daris Basarab.

As pontes e os canais de divulgação estão ainda por tecer e, por isso, esperamos que no futuro mais obras de Eminescu continuem a beneficiar de um louvável trabalho de tradução em Portugal.

\subsection{Lucian Blaga (1895-1961)}

(Re)conhecido poeta romeno, filósofo, dramaturgo, tradutor e diplomata, Lucian Blaga entrelaça os seus caminhos com Portugal entre 1938 e 1939, aquando da sua passagem pela capital lusitana como ministro plenipotenciário da Roménia em Portugal. Autor com quase 40 títulos publicados, Blaga escreve a maior parte dos seus poemas do volume La porțile dorului [Nas Cortes da Saudade] logo depois da sua estadia em Lisboa e em direta ligação com esta.

Começando a sua carreira diplomática em 1922, no período da monarquia, é obrigado a deixar o seu cargo de professor universitário e qualquer função pública em 1948, devido ao regime pro-soviético que começa a instaurar-se no país e que tenta a todo custo silenciar qualquer voz «diferente», marginalizando especialmente os intelectuais proeminentes. Como consequência, desde então até ao fim da vida, fica com um obscuro cargo de bibliotecário e sob uma rigorosa vigilância.

A difusão da obra de Lucian Blaga em traduções portuguesas ${ }^{24}$, começa na Roménia, e não em Portugal, com o volume $A$ milagrosa semente [Mirabila sămânță], publicado em volume bilingue em 1981, em Bucareste, pela editora Minerva, na tradução da mesma Micaela Ghițescu.

Em Portugal, Blaga é publicado em volume quase duas décadas depois, quando o volume La curțile dorului [Nas cortes da saudade], prefaciado por José Augusto Seabra, será vertido para português pela reputada Micaela Ghițescu em 1999 e publicado pela editora Minerva de Coimbra. O volume aproxima duas palavras consideradas únicas em ambas as línguas, já mistificadas em tantas escritas, o dor romeno e a

\footnotetext{
24 Em Maio de 2008, o ICRL em colaboração com a Faculdade de Letras da Universidade de Lisboa e a Revista Steaua de Cluj-Napoca, organiza o colóquio Blaga 70, comemorando 70 anos desde a primeira passagem do poeta por Lisboa. O evento beneficia de uma ampla divulgação, contando com a participação de académicos romenos e portugueses. Os trabalhos apresentados figuram no número especial 8-9 de agosto-setembro de 2008, da Revista Steaua.
} 
saudade portuguesa, que partilham facetas de sentido mas, na visão do poeta, não se confundem perfeitamente, sendo que o dor romeno remete também para a dor, ou uma espécie de dor misturada com saudade. Lucian Blaga manterá os leitmotives que remetem para o seu percurso português: o mar, o navio, a saudade, enquanto elementos simbólicos da espera (Ghițescu 200ob; Zamfir 2004).

\subsection{Mircea Eliade (1907-1986)}

Talvez a personalidade romena mais conhecida em Portugal, Mircea Eliade foi secretário de imprensa junto da embaixada romena na capital portuguesa entre 1941 e 1945. Contudo, permanece na memória coletiva não como diplomata, mas como escritor e sobretudo como grande historiador das religiões, sendo o primeiro a escrever uma história das ideias religiosas.

Das inúmeras obras literárias e tantos outros trabalhos científicos ${ }^{25}$ escritos originalmente em três línguas (romeno, francês e inglês) e traduzidos mundialmente, em Portugal foram publicados os seguintes livros de ficção: Noite Bengali [Maitreyi] (1961), Bosque Proibido [Noaptea de Sânziene] (1973), Rua Mântuleasa [Pe Strada Mântuleasa] (1978), Meia-noite em Serampore 26[Minuit à Serampore] (1990), O romance do adolescente míope [Romanul adolescentului miop] (1993) Isabel e as Águas do Diabo [Isabel et les eaux du diable] (2000), Nas Ciganas Novelas Completas, volume 1 [La Tigănci] (2004), Uma segunda juventude [Le temps d'un centenaire] (2008) ${ }^{27}$.

Em 2008, é publicada pela Guerra e Paz uma obra autobiográfica e memorialista, o Diário Português [Jurnalul Portughez], na tradução de Corneliu Popa. A tradução mais recente, de 2011, é de autoria de Anca Milu-Vaidesegan. Trata-se do seu bastante contestável livro Salazar e a Revolução em Portugal [Salazar şi Revoluția în Portugalia], publicado na Esfera do Caos. Estes últimos dois livros foram traduzidos e publicados com o apoio do TPS e do ICRL.

Os primeiros dois livros, Noite Bengali [Maytrei] (1961) e Bosque Proibido [Noaptea de Sânziene] (1973) são publicados na tradução da Maria Leonor Carvalhão Buescu, pela editora lisboeta Ulisseia. Noite bengali, que poderia ter mantido o título em romeno, Maitreyi, sendo este o nome da personagem feminina, debruça-se sobre a história de amor entre o jovem Eliade (23) e Maitreyi Devi (16), a filha do seu mentor indiano S. Dasgupta. Talvez o mais famoso romance do autor, recebe uma adaptação para cinema (La Nuit

\footnotetext{
25 Embora não seja uma obra literária, não podemos deixar de lembrar o livro publicado pela Livraria Clássica Editora em 1943, Os Romenos, latinos do oriente, pelo seu papel de divulgar a cultura romena em Portugal. Traduzido do francês por Eugénio Navarro, o livro apresenta quadros significativos da história romena em detrimento duma história cronológica.

${ }^{26}$ Tradução do francês de António Vasconcelos.

27 Tradução do francês de Miguel Mascarenhas.
} 
Bengali) em 1988 e um romance resposta escrito pela própria Maitreyi Devi em 1974, It does not die.

O Bosque Proibido (1973) mantém o título que inicialmente lhe foi atribuído na versão original em francês Forêt interdite (1955) e não o título da tradução romena de 1971 Noaptea de Sânziene [Noite de São João]; aprofunda um dos caminhos mais explorados por Eliade, o do espaço e tempo sagrado. Como o próprio autor declara na introdução, este é um livro que pode ser mais chamativo para o leitor português uma vez que parte da ação passa por Lisboa, Cascais e Coimbra.

A mesma editora Ulisseia publica em 1978, desta vez na tradução de Ricardo Alberty, o livro Rua Mântuleasa [Pe Strada Mântuleasa]. Em 1993, na tradução de Manuel Sintra, a Dom Quixote publica um outro romance autobiográfico, $O$ romance do adolescente míope [Romanul adolescentului miop].

\subsection{Ana Blandiana (n. 1942)}

Figura sempre presente nas várias edições dos encontros internacionais de poetas em Portugal, a escritora Otilia Valeria Coman, de seu verdadeiro nome, tem vertido em Portugal o livro Projectos de Passado [Proiecte de Trecut], na tradução de Tanty Ungureanu, sendo o livro publicado pela Cavalo de Ferro em 2005. Amplamente divulgada na Roménia através da sua poesia, dá-se a conhecer ao público português através deste livro de contos, recebido muito bem pela crítica portuguesa se julgarmos pela visibilidade que o livro teve nos canais de imprensa.

Em Portugal, as suas poesias ainda esperam ver a luz em volume individual, apesar de que algumas já constam em coletâneas de poesia, publicadas em consequência dos encontros internacionais de poetas.

\subsection{Gabriela Adameşteanu (n. 1942)}

Escritora da mesma geração, Gabriela Adameşteanu ficou conhecida pelo público português através do livro Uma manhã perdida [O dimineață pierdută] (2012), traduzido por Corneliu Popa, publicado pela Dom Quixote. O volume foi publicado graças aos programas TPS e «20 autores», encabeçando a lista dos títulos recomendados para tradução no exterior.

Uma manhã perdida, romance que descreve quase 70 anos de história romena, fazendo uma crítica ao regime autoritário, trouxe a consagração de Adameşteanu e o prémio da União dos Escritores Romenos em 1984. Também foi indicado para o prémio da União Latina em 2006 e foi adaptado para teatro e rádio.

Em Portugal beneficiou de uma intensa campanha de promoção organizada pelo grupo Leya que, em conjunto com o ICRL, apoiou a vinda da autora a Lisboa. A apresentação do livro, no seu lançamento, ficou a cargo da reputada escritora portuguesa Lídia Jorge. Algumas entrevistas para televisão e jornais asseguraram uma intensa promoção da obra. 
Trata-se de um livro muito denso em romeno, escrito em registos estilísticos variados, que mostram a posição das personagens na sociedade romena. Para certos trechos, que parecem quase impossíveis de verter para português, o tradutor beneficiou dos esclarecimentos autorais.

\section{A voz dos tradutores}

Depois da apresentação de um conjunto de traduções literárias publicadas na Roménia e em Portugal, consideramos imprescindível dar a palavra a alguns dos tradutores graças aos quais a aproximação cultural entre os dois países referidos se tornou mais profunda. Utilizaremos para esta secção fragmentos do livro Intre uitare şi memorie [Entre esquecimento e memória] (2012) de Micaela Ghițescu, entrevistas com Dinu Flămând e Mioara Caragea publicados em revistas culturais romenas e portuguesas, bem como entrevistas concedidas a Iolanda Vasile por Corneliu Popa e Clarisa Lima especialmente para este trabalho.

Formados pela escola de filologia portuguesa da Universidade de Bucareste ou tendo aprendido português como autodidatas, os tradutores literários transformaram a paixão pela língua e cultura em profissão ou, melhor dito, em vocação. Os seus relatos são verdadeiros testemunhos dos avatares das relações culturais romeno-portuguesas.

\subsection{Micaela Ghiţescu (n. 1931)}

$\mathrm{O}$ volume Intre uitare şi memorie [Entre esquecimento e memória] (2012) de Micaela Ghițescu destaca-se principalmente neste aspeto, por oferecer um relato fiel que abrange a dinâmica das traduções literárias na Roménia e em Portugal ao longo de meio século. Um dos aspetos menos conhecidos ao público leitor mais jovem é o papel da censura na época comunista, que determinou mudanças de títulos, alterações ou supressões dos fragmentos considerados inoportunos. Por exemplo, para além do título do romance saramaguiano $O$ memorial de convento, que já mencionámos, Micaela Ghițescu (2012, 141-142) explica como os títulos de dois romances que traduziu, Exílio perturbado [Exil perturbat] (1987) de Urbano Tavares Rodrigues e Silêncio para 4 [Tăcere pentru 4] (1990) de Ruben A. foram modificados em Sfârşit de exil [Fim de exílio] e Singurătate în patru [Solidão em quatro] para serem aprovados pelos censores. A tradutora conta também como eram «adoçados» os fragmentos com cenas eróticas ${ }^{28}$ para não ferir a sensibilidade «realisto-socialista», ou até eliminadas as passagens que continham alusões aos regimes ditatoriais. Parafraseando o injusto adágio traduttore, tradittore, Micaela Ghițescu considera que a essência do trabalho de tradutor pode

\footnotetext{
${ }^{28}$ O romance Os Maias [Familia Maia], publicado com muitos cortes e alterações em 1978, foi reeditado em 2005.
} 
ser melhor exprimida através da expressão traduttore, trudittore ${ }^{29}$, usada por Aurel Covaci.

\subsection{Dinu Flămând (n. 1947)}

Dinu Flămând conta em uma entrevista concedida em 2009 a Ovidiu Şimonca para Observator cultural, que descobriu Fernando Pessoa nos anos '80 e que assim começou a aprender o português. Considera que «a tradução é a melhor e a mais profunda leitura» e que no caso de alguns poemas por vezes podem passar vários anos até encontrar a solução certa. Dinu Flămând fala também da relação entre o ofício de tradutor e a sua própria criação literária, afirmando que a tradução «não é um exercício de estilo ou uma prestação social. É a oportunidade que me ajuda a manter a tensão necessária para a grande arte.»30 $\mathrm{Na}$ entrevista publicada na revista Dilemateca, em 2011, fala sobre as experiências de traduzir os heterónimos pessoanos, cada um com o seu estilo de criação poética, afirmando que a versificação horaciana Ricardo Reis foi a mais difícil de verter para o romeno.

\subsection{Mioara Caragea (n. 1954)}

Numa entrevista concedida à revista Jornal das Letras em 2009, Mioara Caragea considera «um crime dar ao público um livro mal traduzido» e afirma:

a tradução é, em grande medida, uma espécie de hobby, não a faço pelo dinheiro porque eu invisto demasiado tempo numa tradução para que realmente ela seja lucrativa. Traduzo apenas os livros de que gosto, de autores que amo e tenho um grande sentido de responsabilidade não apenas em relação às obras, mas também ao público leitor.

Autora também de estudos críticos, prefácios e de uma tese de doutoramento sobre a relação entre história e ficção na obra de José Saramago, Mioara Caragea acrescenta ao trabalho de tradução, o de interpretação erudita, desvendando significados, alusões, jogos intertextuais.

\subsection{Clarisa Lima (n. 1975)}

Os mais novos tradutores Clarisa Lima e Corneliu Popa são romenos radicados em Portugal, formados em filologia portuguesa na Universidade de Bucareste. Encontraram-se com a tradução por interesse e coincidência, cada um seguindo o seu caminho. Clarisa estreou-se com uma tradução do romance brasileiro Cidade de Deus de

\footnotetext{
${ }^{29} \mathrm{Em}$ romeno, o verbo a trudi, a partir do qual foi criado o termo trudittore, significa, "fazer um trabalho árduo".

30 "Pentru mine, traducerea nu este un exercițiu de stil sau o prestație socială. Este prilejul de a-mi menține tensiunea de care am nevoie în marea artă” (Dinu Flămând, 2009).
} 
Paulo Lins, uma verdadeira provocação e um «choque profissional», que certamente a preparou para as duas traduções de Peixoto.

Profissional extremamente perfecionista, Clarisa Lima confessa que traduzir Peixoto, tendo ele um estilo muito poético e por isso difícil de transpor, a atormentou constantemente e ainda o faz. «Acabei o trabalho com um aperto de coração, com a sensação de ser um trabalho que nunca pode acabar, que nunca deve acabar», diz a tradutora na entrevista que nos concedeu em finais deste mês. É o sonho de cada tradutor poder contactar com o escritor que traduz. É este o privilégio, na maioria dos casos, quando se trata de autores contemporâneos. Clarisa Lima confirma-nos que o contacto com o autor português que queria ver os seus livros traduzidos para o romeno, a ajudou a esclarecer algumas dúvidas em relação aos textos.

Não por último, subscrevendo as palavras da professora Mioara Caragea, confirma-nos que o trabalho de tradução é antes de tudo uma paixão, pois

Já se sabe, há muito tempo, que os tradutores da Roménia trabalham mais pelo prazer de traduzir do que para se sustentarem, e a situação chega a ser ridícula. Os preços irrisórios por página podiam desanimar, à partida, qualquer tradutor dos outros países da Europa. [...] Penso que, unidos, os tradutores romenos podem alterar a situação, para receberem um tratamento mais digno, mas é uma "luta" que vai levar muito tempo e que está a ficar cada vez mais difícil por causa da crise geral. Entretanto, vamos fazendo uma espécie de voluntariado. (Lima 2013)

\subsection{Corneliu Popa (n. 1971)}

Corneliu Popa tem o grande mérito de verter para português obras romenas, uma opção louvável, enquanto nativo de romeno e não de português, mas para ele é uma escolha natural, uma vez que os primeiros trabalhos foram de interpretação de romeno para português. Radicado há quase duas décadas em Portugal, afirma sentir-se distante da língua romena atual, «irreconhecível quase», com muitos empréstimos de inglês, muito simplificada, que parece ter perdido o seu encanto. Com experiência variada na área de traduções, Corneliu confessa que gosta mais de poesia e que já verteu para português poetas romenos como Ana Blandiana, Marin Sorescu ou Mircea Dinescu, publicados em diversas coletâneas. Reconhece o gosto por traduzir poesia, que por ser mais difícil e desafiador, acaba tendo um retorno mais gratificante.

Sempre que possível, beneficiou da colaboração dos autores que verteu para o português, sendo a tradução de Uma manhã perdida impossível sem a participação de Gabriela Adameşteanu, pois «se trata de três livros em um». Dada a densidade do romance, pensa que ser nativo romeno e com uma bagagem cultural que o aproxima do livro, trabalhou a seu favor, facilitando a compreensão da narrativa e a própria tradução. Também reconhece que foi este o livro mais difícil de traduzir, durando cerca de seis meses o processo efetivo. Corneliu Popa 
opta por manter a estrutura fraseológica e as palavras muito similares à língua original porque, por terem estruturas próximas, o romeno e o português permitem isso.

Traduzir o Diário português de Mircea Eliade não foi difícil, tratando-se de uma linguagem acessível. Além do mais, tendo o autor já falecido, coube-lhe uma envolvência maior no processo de promoção do livro, através das entrevistas concedidas.

Foi nosso propósito, através destes depoimentos, dar voz aos principais atores, responsáveis pelo conhecimento mútuo das duas literaturas. Esperamos que assim ganhem cada dia mais voz, mais visibilidade e reconhecimento, porque são os elementos chave deste processo, mostrando sentidos e enriquecendo os nossos mais valiosos momentos que só podem surgir na intimidade de certos livros.

\section{À guisa de conclusão}

É papel de cada artigo ou indagação escrita não oferecer respostas, mas antes levantar mais perguntas, ou colocar as perguntas certas. Portanto, em jeito de conclusão queremos rever algumas questões que ficam em aberto e que achamos merecerem destaque em futuros trabalhos. Depois de termos constatado uma realidade óbvia que, parcialmente já intuíamos, nomeadamente a existência de mais traduções de autores portugueses em romeno do que o contrário, ficámos surpreendidas em descobrir um maior número (do que o esperado) de traduções romenas em Portugal. Notámos que parte deste trabalho é fruto da disseminação de figuras canónicas da cultura romena, como é o caso de Mircea Eliade, Emil Cioran ou Eugen Ionescu. No entanto, a tradução de autores contemporâneos de ficção é uma promessa de um bom futuro, se o empenho conjunto e conjuntural permitir.

Verificamos que parte das obras mais difundidas, associadas às personalidades de Cioran e Ionesco, se baseiam nas versões em francês das respetivas obras, facto nada surpreendente porque foi esta a língua que os autores preferiram a partir do seu exílio francês.

Saudamos os programas de apoio à tradução, mas esperamos ver maior «eficácia» por parte dos mesmos, como se tem verificado em outros países e como fomos assegurados pelo ICRL, que diz não poupar esforços neste sentido.

Achamos importante explorar em futuros trabalhos algumas das traduções às quais nos referimos neste ensaio, especialmente de Saramago ou Adameşteanu. Paralelamente, é importante salientar novamente que esta pesquisa, longe de ser exaustiva, optou pelo óbvio recorte a Portugal, deixando de fora os outros espaços falantes de português, nomeadamente a exploração das traduções romenas no Brasil e o contrário, tarefa pendente que acreditamos vir a ser gratificante ${ }^{31}$

${ }^{31} \mathrm{O}$ confronto entre as traduções romenas de literatura brasileira e as traduções dos autores romenos publicadas no Brasil foi brevemente feito por Lungu-Badea (2012). 


\section{Referências bibliográficas}

Adameşteanu, Gabriela. Uma manhã perdida. Trad. Corneliu Popa. Lisboa: Dom Quixote, 2012.

Blaga, Lucian. Nas cortes da Saudade. Trad. Micaela Ghițescu. Coimbra: Minerva, 1999.

Blaga, Lucian. A milagrosa semente. Trad. Micaela Ghițescu. Bucareşti: Minerva, 1981.

Blandiana, Ana. Projectos de Passado. Trad. Tanty Ungureanu. Lisboa: Cavalo de Ferro, 2005.

Bloom, Harold. The Western Canon: The Books and School of the Ages. New York: Harcourt Brace \& Company, 1994.

Camões, Luís Vaz de. Lusiada. Trad. Aurel Covaci. Bucureşti: Editura pentru Literatură Universală, 1965.

Camões, Luís Vaz de. Sonete. București: Editura Univers, 1974.

Camões, Luís Vaz de. Lusiada. Trad. Aurel Covaci. Bucureşti: Minerva, 1977. Caragea, Mioara. A leitura da história nos romances de José Saramago. Bucureşti: Editura Universității din Bucureşti, 2003.

Eliade, Mircea. «Camões şi Eminescu». Acção. 1942. In Camões şi Eminescu. Bucureşti: Ed. Libra, 2000: pp. 53-66.

Eliade, Mircea. Os romenos, Latinos do Oriente. Lisboa: Livraria Editora Classica, 1943.

Eliade, Mircea. Noite Bengali. Trad. Maria Leonor Carvalhão Buescu. Lisboa: Editora Ulisseia, 1961.

Eliade, Mircea. Bosque Proibido. Trad. Maria Leonor Carvalhão Buescu. Lisboa: Editora Ulisseia, 1973.

Eliade, Mircea. Rua Mântuleasa. Trad. Ricardo Alberty. Lisboa: Editora Ulisseia, 1978.

Eliade, Mircea. Meia-noite em Serampore. Lisboa: Difel, 1990.

Eliade, Mircea. O romance do adolescente míope. Trad. Manuel Sintra. Lisboa: Dom Quixote, 1993.

Eliade, Mircea. Isabel e as Águas do Diabo. Lisboa: Livros do Brasil, 2000.

Eliade, Mircea. Nas Ciganas Novelas Completas, volume 1. Trad. Anca Ferro. Lisboa: Cavalo de Ferro, 2004.

Eliade, Mircea. Uma segunda juventude. Cascais: Bico de Pena, 2008.

Eliade, Mircea. Diário Português. Trad. Corneliu Popa. Lisboa: Guerra e Paz, 2008.

Eliade, Mircea. Salazar e a Revolução em Portugal. Trad. Anca MiluVaidesegan. Lisboa: Esfera do Caos, 2011

Fonseca, Fernando Venâncio Peixoto da. «Relações Histórico-Culturais LusoRomenas». Boletim de Trabalhos Históricos. Vol. XL, 1989: 111-128. URL: http://www.amap.com.pt/uploads/p/bth/1989/ bth1989_05.pdf (Consultado a 26 de agosto de 2013)

Eminescu, Mihai. Eminescu. Poezii. Trad. Victor Buescu. Lisboa: Fernandes, 1950.

Eminescu, Mihai. Poesias. Trad. Daris Basarab. Bucareste: Boris Davis, 2004. Eminescu, Mihai. Revedere. Trad. Doina Zugrăvescu. Castelo Branco: Evormons, 2005.

Eminescu, Roxana. Preliminarii la o istorie a literaturii portugheze. Bucureşti: Editura Univers, 1979. 
Eminescu, Roxana. Novas coordenadas do romance português. Lisboa: ICALP, 1983 .

Ghițescu, Micaela. «Destino de Eça de Queirós na Roménia através das traduções». Revista Camões. No 9/10, 2000a: 249-257.

Ghițescu, Micaela. «Cultura luso-brasileira na Roménia». Veredas, Revista da Associação Internacional dos Lusitanistas. 3-II, Porto, 200ob: 589-595.

Ghițescu, Micaela. Intre uitare şi memorie. Bucureşti: Humanitas, 2012.

Lungu-Badea, Georgiana. "La traduction comme espace de confrontation et d'affrontement des langues dites «majoritaires» et «minoritaires»". Traduzires, vol 1, $\mathrm{n}^{\mathrm{O}}$ 1, 2012. Universidade de Brasília. URL: http://seer.bce.unb.br/index.php/ traduzires/article/view/6653 (Consultado a 27 de agosto de 2013).

Peixoto, José Luís. Nici o privire. Trad. Clarisa Lima. Iaşi: Polirom, 2009.

Peixoto, José Luís. Cimitirul de piane. Trad. Clarisa Lima. Iaşi: Polirom, 2010.

Perdigão, Daniel Silva. As relações culturais luso-romenas. Dissertação de mestrado. Universidade Aberta. Lisboa, 1998.

Pessoa, Fernando. Ploaie oblică. Trad. Roxana Eminescu. Bucureşti: Editura Univers, 1980.

Pessoa, Fernando. Păstorul de turme. Edição trilingue. Craiova: Europa, 1992.

Pessoa, Fernando. Bancherul anarhist. Trad. Micaela Ghițescu. Bucureşti:

Editura Est, 1995.

Pessoa, Fernando. Terapia eliberării. Trad. Micaela Ghițescu. Bucureşti: Editura Ştiințifică, 2000.

Pessoa, Fernando. Cartea neliniştirii. Trad. Dinu Flămând. 2 vol. Bucureşti: Editura Fundației Culturale Române, 2000.

Pessoa, Fernando. Odă maritimă şi alte poeme. Trad. Dinu Flămând. Bucureşti: Editura Univers, 2002.

Pessoa, Fernando. Ode şi alte poeme. Trad. Dinu Flămând. Piteşti: Editura Paralela 45, 2004.

Pessoa, Fernando. Cartea neliniştirii. Trad. Dinu Flămând. Ed. revista e completada. Bucureşti: Humanitas, 2009.

Pessoa, Fernando. Opera poetică. Trad. Dinu Flămând. Bucureşti: Humanitas, 2011.

Pessoa, Fernando. Ultimatum şi alte manifeste. Trad. Dinu Flămând e Micaela Ghițescu. Bucureşti: Humanitas, 2012.

Pessoa, Fernando. Ploaie oblică. Trad. Dinu Flămând. Audiobook. Bucureşti: Humanitas Multimedia, 2012.

Pîrvan-Jenaru, «Excelența literaturii lui Peixoto». Observator cultural, $\mathrm{n}^{\mathrm{o}}$ 538, 2010. URL: http://www.observatorcultural.ro/ Excelenta-literaturii-luiPeixoto*articleID_24159-articles_details.html (Consultado a 26 de agosto de 2013)

Ploae-Hanganu, Mariana. «O ensino e a promoção do português na Roménia». Terminologie et traduction. O português, língua de comunicação internacional. No 1, 1995: 231-238.

Saramago, José. Memorialul de la Mafra. Trad. Mioara Caragea. Bucureşti: Editura Univers, 1988.

Saramago, José. Pluta de piatră. Trad. Mirela Stănciulescu. Bucureşti: Editura Univers, 1990.

Saramago, José. Istoria asediului Lisabonei. Trad. Mioara Caragea. Bucureşti: Editura Univers, 1997.

Saramago, José. Memorialul mînăstirii. Trad. Mioara Caragea. Bucureşti: Editura Univers, 1998. 
Saramago, José. Evanghelia după Isus Cristos. Trad. Mioara Caragea. Bucureşti: Univers, 1999.

Saramago, José. Toate numele. Trad. Mioara Caragea. Iaşi: Polirom, 2002.

Saramago, José. Anul morții lui Ricardo Reis. Trad. Mioara Caragea. Iaşi: Polirom, 2003.

Saramago, José. Eseu despre orbire. Trad. Mioara Caragea. Iaşi: Polirom, 2005 .

Saramago, José. Peştera. Trad. Mioara Caragea. Iaşi: Polirom, 2005.

Saramago, José. Intermitențele morții. Trad. Georgiana Bărbulescu. Iaşi: Polirom, 2007.

Saramago, José. Eseu despre luciditate. Trad. Georgiana Bărbulescu. Iaşi: Polirom, 2008.

Saramago, José. Omul duplicat. Trad. Georgiana Bărbulescu. Iaşi: Polirom, 2009.

Saramago, José. Fărâme de memorii. Trad. Georgiana Bărbulescu. Iaşi: Polirom, 2009.

Saramago, José. Caietul. Texte scrise pentru blog: septembrie 2008 - martie 2009. Trad. Simina Popa. Iaşi: Polirom, 2010.

Saramago, José. Călătoria elefantului. Trad. Mioara Caragea. Iaşi: Polirom, 2010.

Saramago, José. Manual de pictură şi caligrafie. Trad. Georgiana Bărbulescu. Iaşi: Polirom, 2010.

Saramago, José. Călătorie prin Portugalia. Trad. Mirela Stănciulescu. Iaşi: Polirom, 2011.

Saramago, José. Ultimul caiet. Texte scrise pentru blog: martie 2009 noiembrie 2009. Trad. Simina Popa. Iaşi: Polirom, 2011.

Saramago, José. Cain. Trad. Simina Popa. Iaşi: Polirom, 2012.

Saramago, José. Lucarna. Trad. Simina Popa. Iaşi: Polirom, 2013.

Stoica, Alina. Relații diplomatice româno-portugheze (1919-1933). Martinho de

Brederode - ambasador la Bucureşti. Oradea: Editura Universităţii din Oradea, 2011.

Vários autores. Dois mil e quatro-antologia Literária. Trad. Vários tradutores. Lisboa: Cavalo de Ferro, 2004.

Zamfir, Mihai. Formele liricii portugheze. București: Editura Univers, 1985.

Zamfir, Mihai. "José Luís Peixoto». România literară, $\mathrm{n}^{0} 31$, 2002. URL: http://www.romlit.ro/jos_lus_peixoto (Consultado a 26 de agosto de 2013)

Zamfir, Mihai. Formele liricii portugheze. $2^{\mathrm{a}}$ edição. Piteşti: Paralela 45, 2003. Zamfir, Mihai \& Perdigão, Daniel. «Craii de Curtea Veche. Un prototip portughez al lui Pantazi». România literară, $\mathrm{n}^{0}$ 47, 1998: 12-15.

Zamfir, Mihai. «Portugal visto de Bucareste: os romenos da Ibéria têm mais sorte». Janus, no 98, 2004. URL: http://janusonline.pt/1998/1998_5_4.html (Consultado a 26 de agosto de 2013).

Zamfir, Mihai. «Revedere mult aşteptată». România literară no 14, 2005. URL: http://www.romlit.ro/revedere_mult_ateptat (Consultado a 26 de agosto de 2013). 